\title{
DESCRIÇÃO SEMÂNTICA E POSTULAÇÃO DE ENTIDADES
}

\author{
Celso R. Braida \\ Universidade Federal de Santa Catarina \\ braida@cfh.ufsc.br
}

\begin{abstract}
RESU M O : N esse artigo eu proponho, partindo da distinção entre conceitos semânticose conceitos ontológicos, a separação entre descrição semântica e postulação de entidades. A postulação de uma entidade implica o fornecimento de um critério de identificação, isto é, a verdade de uma asserção de identidade en tre dois dispositivos de designação. Isso parece in dicar que a existência da entidade seria garantida pela simples existência de um critério de identificação. Porém, esta é uma condição de significatividade para um termo referencial: que ele codifique ou esteja associado a uma descrição identificadora. Tal descrição identificadora não pode, de modo algum, ser confundida com uma condição de existência para a entidade em questão.
\end{abstract}

Palavras-chave: Significatividade, entidade, semântica, existência.

No cerne da semântica está a distinção entre a palavra e 0 objeto, entre o sinal utilizado para designar um objeto e o objeto designado, bem como entre propriedades de sinais significativos e propriedades de objetos, a ponto de o não-reconhecimento dessa distinção ser posto como um dos erros básicos que a análise lógicosemântica viria corrigir. ${ }^{1}$ Em razão disso, pode parecer que uma teoria semântica estaria habilitada a explanar a estrutura da relação entre a linguagem e a realidade. Porém, eu espero mostrar que essa possibilidade éuma ilusão. Para isso, proponho uma conceitualização em que a significatividade é instaurada pel os nexos de remissão ao contexto e à situação, e que tais nexos de remissão pressupõem a distinção entre 0 sinal e algo diferente dele, seja um outro sinal, seja um objeto ou domínio de objetos. Essa solução, porém, permanece obscura, pois os conceitos de objeto e de domínio de 
objetos não são claros, sendo confusa a conexão teórica entre propriedades (semânticas) de sinais e propriedades (ontológicas) de objetos e de domínios de objetos, conquanto essa conexão seja relevante para a descrição do conteúdo semântico sentencial.

Para elucidar esse ponto considerarei duas questões. Primeiro, a questão das implicações existenciais da atribuiç̧ão de significação determinada a uma sentença, isto é, a questão da relação entre a significatividade e a existência de entidades. Segundo, a questão das relações entre princípios semânticos e princípios ontológicos, sobretudo entre os princípios da substituibilidade e de equivalência semântica e o princípio de identidade para objetos. Em relação à primeira questão vou defender que a determinação do objeto de referência, envolvido na descrição do conteúdo semântico das sentenças com palavras referenciais, resulta da fixação da contribuição de um plexo de fatores que extrapola a noção de significatividade (seja el a fregeana ou não), no sentido de que a descrição das propriedades semânticas de um sinal utilizado para designar um objeto não é ainda suficiente para determinar o referente, sem a descrição do contexto discursivo e da situação de proferimento. 0 que é uma decorrência, pela inversão do raciocínio, do fato de que a existência da entidade referida não é garantida pela boa formação semântica de uma sentença sobre essa entidade. Por um lado, porque as noções ontológicas não são derivadas das estruturas e noções lingüístico-semânticas, embora a correlação entre el as esteja no cerne da significatividade. Por outro, porque a semântica formal apenas poderia estabelecer a ontologia do domínio de referência na medida em que fossem confundidas as condições de referência a um objeto com as condições de existência de um objeto. Desse modo, a resposta para a segunda questão já está antecipada. Em relação à segunda vou defender a posição de acordo com a qual regras e princípios semânticos são concebidos como fundados em princípios ontológicos, embora essas regras e princípios sejam autônomos, pois a aceitação de uma semântica determinada não implica a aceitação de uma ontologia determinada. A estratégia para justificar essa 
posição, por um lado, será a de reforçar a tese da exterioridade da relação semântica e a tese da autonomia da significatividade em relação à existência, o que farei através da distinção entre objeto de discurso e entidade referida.

1. A primeira questão a se considerar dizrespeito às implicações existenciais da determinação do conteúdo semântico sentencial e da contribuição semântica dos sinais subsentenciais. ${ }^{2}$ A bordarei esse tópico a partir da definição clássica de termo proposicional, relembrando que os termos são definidos como "uma expressão que nomeia ou que se aplica a uma coisa ou coisas, de algum tipo, real ou pen sada". ${ }^{3}$ Enquanto tal, essa definição não exige a existência do que é nomeado ou designado. Porém, se é o caso que para uma palavra ser um termo ela tem de designar ou aplicar-se a alguma coisa, então, cabe a pergunta pelo estatuto ontológico dessa coisa designada, sobretudo quando ela é meramente pensada.

Denominemos "objeto" esse correlato dos termos. Agora, restam as questões: todos os correlatos são do mesmo tipo? O u os objetos designados são todos da mesma categoria ontológica? A lém disso, faz alguma diferença semântica o fato de alguns objetos existirem e outros não?E se fosse estipulado denominar "entidade" as coisas existentes sem relações com os termos, todos os objetos correlatos de termos, inclusive os meramente pensados, seriam entidades? Caso a resposta seja não, como então conceitualizar e descrever as propriedades semânticas das palavras a eles aplicadas ou que os designam? C aso a resposta seja sim, como então conceitualizar essas entidades e, sobretudo, como el as se relacionam com o domínio de objetos de referência real?

U ma vez que certas palavras têm sua contribuição semântica, em certos contextos, determinada pela existência ou não de um objeto de referência, conhecer o significado dessas palavras parece implicar conhecer o objeto que ela designa. Isso acarretaria que as propriedades semânticas das sentenças em que essas palavras ocorrem apenas fossem determinadas por meio da identificação de 
um objeto. M as, se for admitida a hipótese de que o objeto apenas se deixa identificar pelo modo como ele é significado pela palavra que o designa, como explanar a significatividade da palavra? Tratase de enfrentar a questão do como da determinação daquilo do que se está a falar, e em que medida essa determinação é relevante para a significatividade de certas palavras. 0 que se quer saber é se é possível determinar como é significativa uma sentença com uma palavra referencial, sem passar pela determinação do objeto referido.

$\mathrm{N}$ a medida em que a relação com al go diferente é necessária para a linguagem ser significativa, ou, ao menos, para se reconhecer um sistema de sinais como linguagem, a determinação de al go como objeto parece ser a condição necessária para a significatividade de algumas palavras em uso. Em não havendo como determinar 0 objeto de referência de um termo designador, para mencionar um caso, não haveria significado determinado para certas palavras. A determinação do objeto de referência, por conseguinte, seria uma condição para a determinação do conteúdo semântico da sentença inteira contendo tal termo.

D essa hipótese surgem duas estratégias de conceitualização: uma se define pela hipótese de que o objeto é uma contraparte hipostasiada, uma projeção da significatividade de certas palavras, no sentido de que a noção de objeto seria dependente da noção de termo designador; outra, porém, põe os objetos como determinados antes e independentemente da linguagem, fazendo, ao contrário, a noção de palavra significativa e designadora depender da noção de objeto determinado. Essas duas alternativas são compatíveis, respectivamente, com as propostas inferencialista e referencialista ${ }^{4}$ de explanação do conteúdo semântico. Todavia, resta ainda uma terceira hipótese, a saber: que a determinação do objeto seja dependente da determinação da significatividade, mas que esta também seja dependente daquela, ambas sendo logicamenteinterconectadas. 0 conteúdo semântico de uma sentença com palavras referenciais seria, então, dependente da existência dos objetos referidos, mas 
estes, por sua vez, apenas seriam determinados por meio das indicações semânticas codificadas nas sentenças acerca deles.

Considere-se o uso da palavra "H omero", que sustenta em nossa língua o conteúdo semântico de muitas sentenças, apesar de ninguém até hoje poder determinar de que indivíduo particular se está a falar quando se usa tal nome próprio. Isso significa que as sentenças em que esse nome ocorre não têm significação determinada?

A posição aqui defendida éa de quea atribuição de referencialidade a uma palavra implica a suposição da existência do objeto por ela referido, e que a asserção de existência de um objeto implica referi-to de algum modo. Para isso, faz-se necessário fornecer um meio de identificação do objeto que o distinga de todos os demais, e isto não é senão introduzir na linguagem uma palavra que 0 designe. Isto é, para que um objeto seja tido como existente, faz-se necessário o fornecimento de um critério de identificação para 0 objeto, o que não é senão estabelecer a verdade de uma asserção de identidade com duas palavras designadoras. Isso pareceria indicar que a existência do objeto ou da entidade estaria garantida pela simples existência de um critério de identificação. Todavia, esta é uma condição de significatividade para um termo referencial: que ele veicule ou esteja associado a uma descrição identificadora. De modo algum, tal descrição identificadora pode ser confundida com uma condição de existência para o objeto em questão. Do fato que se tenha uma descrição identificadora associada ao nome "H omero" não se segue que exista alguém que a satisfaça. $M$ as, a existência dessa condição é suficiente para tornar significativo o nome, isto é, é suficiente para introduzi-to como palavra referencial que pode ser então utilizada como termo singular em uma sentença, por exemplo, "H omero jamais existiu".

Essa imagem é todavia parcial. Ela não leva em consideração os recursos da linguagem que permitem a introdução de objetos diretamente no discurso sem recorrer-se ao campo lingüístico já solidificado. A codificação de uma descrição identificadora não é 
uma condição necessária, pois uma palavra referencial pode ser introduzida sem que se Ihe associe uma caracterização do objeto nomeado. No modo da designação formal, o que é codificado pela palavra referencial apenas permite a identificação do objeto pelo agenciamento de vínculos com a situação e o contexto. N esse modo de significação, o que garante a unicidade da referência não é fornecido pelo termo designador, mas antes é uma conseqüência da conjunção de um contexto discursivo e de uma situação de proferimento. ${ }^{5} 0$ que implica que uma sentença pode tratar de um objeto sem que, nela, uma palavra precise codificar uma condição identificadora desse objeto.

Para melhor compreensão, considere-se as sentenças:

(1) Este menino chamar-se-á "Pedro", porque ele foi encontrado sobre uma pedra.

(2) Pedro nada sabe acerca de sua mãe, porque ele foi encontrado sobre uma pedra.

Na primeira sentença, as ocorrências das palavras "Este" e "ele" cumprem seu papel referencial sem que, a elas, esteja associado um critério de identificação do objeto referido. Não significa isto, porém, que um objeto não seja identificado na situação-contexto. A ntes, o que ocorre é que tais palavras codificam precisamente, sua significação, tal é a dependência dessa situação-contexto. Se, para que objetos fossem introduzidos no discurso, devêssemos sempre dispor de um critério de identidade discursivo que os distinguisse dos demais e permitisse reconhecê-los como os mesmos, então tais palavras, não obstante serem referenciais, não introduziriam um objeto através de uma descrição que unicamente se valesse desse objeto. 0 que em parte é verdade: elas não introduzem um objeto, mas isso não impede que as sentenças de que elas fazem parte sejam sobre um objeto determinado. Se ali um objeto é apanhado pela inteira sentença como al go sobre o que se dizalguma coisa, ele não é dado por meio de um critério de identidade expresso pela expressão demonstrativa. ${ }^{6}$ 
Por conseguinte, a qualificação de uma palavra como termo referencial não exige que ela veicule uma condição de identidade, nem sequer uma condição de identificabilidade, mas tão-somente que ela marque uma posição referencial que possa ser retomada por anáfora. As retomadas revelarão aos poucos se o termo refere ou não. N o primeiro caso, a palavra "Este" faz uma indicação formal de um objeto que é retomado pela palavra "ele". C aso não haja um tal objeto - ou não se possa, no transcorrer das retomadas, identificá10 - , o contexto inteiro deixa de ter um conteúdo semântico determinado. D esse modo, pode-se explicar a noção de objetos meramente pensados, correlatos de termos que não designam objetos reais.

C onsidere-se agora, para fins de contraste, o papel das ocorrências da palavra "Pedro". Em conformidade com a ortodoxia, marquei a diferença de papel semântico da ocorrência dessa palavra em (1) com o emprego de aspas, indican do assim a sua mera menção, para diferenciar do seu uso em (2) (embora o contexto torne isto supérfluo). Em (1) tal palavra não éum termo proposicional, isto é, não designa nem se aplica a nenhum objeto - ela aparece ali apenas qua objeto-sinal. 0 utra maneira de explicar essa diferença, contudo, édizer queem (1) tal palavra foi introduzida (não sendo significativa) e que em (2) ela é utilizada (portanto, como já significativa).

A palavra "Pedro" em (2), tal como "Este" em (1), éreferencial, o que significa dizer que é por meio dela que a sentença inteira diz algo sobre um objeto. A inexistência de um referente faz desmoronar o conteúdo semântico da sentença inteira. Então, podemos dizer que em (1) a palavra "Este" introduz uma entidade no discurso, a qual, na medida em que for apanhada e alocada no campo discursivo por meio de retomadas anafóricas e predicações, poderá vir a ser um objeto com propriedades determinadas. A distinção entre objeto e entidade, como correlatos dos termos, não éontológica, pois com ela quero marcar uma distinção semântico-descritiva, a saber, a distinção entre, de um lado, a introdução de uma palavra referencial a partir de uma outra palavra (em geral, outras) que codifica uma descrição identificadora, e, de outro, a introdução de 
uma palavra referencial via uma outra palavra dêitica. Distinção esta que nos exemplos explana a diferença semântica das palavras "Este" e "Pedro".

A penas a confusão entre condições de existência e condições de significatividade, resultado da não-distinção entre entidade e objeto, possibilita que se diga que uma sentença cujo termo singular não designa é assignificativa. Nesse caso, a existência é como que engolida pela significatividade, tornando-se apenas um ponto relativo na trama de significações engendráveis em uma linguagem. Essa imagem, entretanto, supõe que a significatividade das palavras seja determinada sem recorrer-se a relações extralingüísticas e, portanto, que a significatividade seja anteriormente definida. 0 que, em geral, está associado à tese de que a noção de entidade é superveniente e dependente em relação à significatividade. Por isso, admitidas essas distinções, não seria semanticamente inadequado dizer que H omero, como objeto de discurso, pode não ter existido - como entidade. Em termos semânticos isso significaria apenas que o uso do nome "H omero" não pode ser revertido, por meio de uma cadeia anafórica, ao uso de uma palavra dêitica.

0 ponto defendido aqui, por conseguinte, é o de que essa precedência da significatividade apenas tem sentido quando está em questão a noção de objeto, mas que essa precedência é indefensável no que se refere à noção de entidade. Disso se segue que a hipótese oposta também não é correta, a saber, que o objeto preceda a significatividade. $\mathrm{N}$ em uma nem outra podem ser ditas. 0 que se pode dizer é que significatividade e objetalidade são categorias indissociáveis: se parto de uma linguagem efetiva, os objetos serão decorrentes das articulações lingüísticas, na medida em que estas fornecem uma armação em que os tipos possíveis de objetosjá estão dados; no entanto, se parto de um sistema de objetos determinados, então já possuo tudo o que énecessário para introduzilos em um discurso, para dizêlos em uma linguagem. Exercer uma linguagem e dominar um sistema de objetos, nessa perspectiva, se equivalem, tal como prevê a tese lingüístico-inferencial; mas não 
pelas razões que ela alega. Tal como prevê a tese ontológicoreferencial, a existência de entidades não é garantida pela simples existência de palavras significativas, nem também pelas razões que ela apresenta.

Explico-me: a identificabilidade não define a noção de entidade como objeto de referência, mas, ao contrário, é a identificabilidade que pressupõe a existência. A identificabilidade, porém, funda a significatividade que permite dizer ou introduzir as entidades como objetos dediscurso, possibilitan do a instituição de uma palavra designadora de uma entidade, disponibilizando-a como objeto para o discurso. Porém, se a entidade, ou existência, é uma condição de possibilidade da identificabilidade, a qual está por detrás da significatividade determinada, ${ }^{7}$ também o é a significatividade, pois, sem um sistema de predicados aplicáveis às entidades referidas, não se pode caracterizar algo como tendo esta ou aquela propriedade. Em suma: as noções de objeto e de critério de identidade são concomitantes com a formação da dizibilidade e da significatividade, porém a existência de entidades não.

2. Considere-se agora a questão levantada por Q uine, em Sobre 0 que há, ${ }^{8}$ acerca de como responder a uma pergunta ontológica. 0 ponto defendido por ele é 0 de que do fato que possamos afirmar ou negar algo de algo não se segue que algo deva ser ou existir. A utilização de designadores que supostamente teriam como referentes entidades fictícias, possíveis, impossíveis etc. não nos comprometeria com a existência de entidades. A razão: "um termo singular não precisa nomear para ser significativo". ${ }^{9}$ N omear, nesse contexto, é referir, e referir sim exigiria a existência do referente. 0 mesmo raciocínio aplicar-se-ia aos termos gerais, os quais, embora significativos, não nomeariam algum tipo especial de entidade.

Todavia, de modo algum Q uine está afastando-se da noção de termo citada no início, muito pelo contrário. 0 que ele faz é aplicar a teoria das descrições de R ussell, de tal modo que palavras aparentemente referenciais sejam analisadas de modo que sua 
significatividade revele-se ser contextual. Sentenças com nomes descritivos complexos, ou descrições definidas, e nomes próprios ocupando a posição de termo singular, quando bem analisadas, deixam de conter qualquer palavra referencial, de tal modo que a significatividade da inteira sentença não exige a existência de uma entidade. Propriamente falando, portanto, tais palavras não são termos.

Do ponto de vista estrito da descrição semântica, essa solução é embaraçosa. Primeiro, porque tem de supor que as palavras em posição de termo singular, na real, não são termos singulares, nem são referenciais. Seja a frase "O autor de Waverley"; conforme a análise de R ussell-Q uine,

essas palavras, longe de pretenderem ser nomes especificamente do autor de Waverley, não pretendem absolutamente ser nomes; referem-se a entidades em geral, com uma espécie de ambigüidade intencional que Ihes é peculiar. ${ }^{10}$

Todavia, o que é para uma palavra "pretender ser nome"? Como distinguimos as palavras que pretendem ser daquelas que realmente são? C omo compreender essa referência a entidades em geral?

Do fato de que se admita a tese, segundo a qual de uma palavra não é necessário "exigir referência objetiva para ser de alguma maneira significativa", 11 não se segue que a única maneira de implementá-la seja postulando que "um termo singular não precisa nomear para ser significante" e dizendo que "há um abismo entre significar e nomear". ${ }^{12}$ A solução de Quine, entretanto, está orientada pelo salutar desejo de evitar a reificação das significações das palavras. Aquilo contra o que ele constrói a sua alternativa é a confusão entre "o suposto objeto nomeado com o significado da palavra". ${ }^{13}$ A solução consiste em mostrar que nem sempre significar é nomear, ou, então, em reduzir a função de nomear uma forma de significar que não exija a hipóstase de entidades ali onde não há nada, sobretudo ali onde tão-somente há palavra. 
0 problema aqui abordado não é exatamente esse, contudo, poisa significatividadenão se confunde com objetos, e muito menos com entidades, já que o aceitamos logo ao tomá-la como uma relação. 0 que quero questionar antes é al go aceito sem mais delongas por Q uine, a saber: que seja preciso abandonar o plano semântico para explanar as propriedades semânticas de palavras que não referem. Com efeito, para ele o conteúdo de tais palavras é uma decorrência de uma intenção de referir ali onde não há referente algum. Essa saída é necessária para Q uine justamente porque el e enten de que, se uma palavra é um termo, ela tem de referir (designar ou aplicarse a alguma coisa), do contrário ela tem de ser analisada de modo a revelar a sua natureza de pseudotermo.

Todavia, a introdução, na descrição semântica, de fatores pragmático-intencionais é equivalente à denegada introdução de entidades intensionais, e, do ponto de vista da teoria semântica, ambos os procedimentos apelam para fatores exteriores à semântica. Penso que é possível sustentar uma teoria da explanação semântica sem apelar para entidades e fatores dúbios - sejam eles objetos intensionais, intenções, ou lances pragmáticos. Essa recusa não tem sua motivação em um desejo de redução, mas sim é a tentativa de manter-se no plano semântico. Também não significa recusar 0 enraizamento da significatividade nas ações e inten ções dos usuários da linguagem, mas constitui antes a defesa da hipótese de que, no procedimento de análise semântica, apenas aqueles fatores já lingüísticos deveriam ser utilizados, isto baseado na intuição de que o nexo a ser explanado é semântico. D esse modo, pretendo combinar no procedimento descritivo a recusa de entidades intencionais e intermediários semânticos, defendendo uma "directness of the language-world relationship", ${ }^{14}$ com a abdicação do uso de fatores não-semânticos, tudo isso em nome da autonomia da semântica. Para isso, recorro apenas a entidades e fatores efetivos, quais sejam a situação, o contexto, e aos modos de significação determinados pela introdução da palavra na linguagem e pelas cadeias anafóricas e inferenciais. 
0 que decide se uma palavra refere ou não é o modo como ela foi introduzida na linguagem que se está a usar. Q ue um nome, "Sócrates" ou "D ionísio", refira ou não, portanto, não éuma propriedade dessas palavras em particular e dos nomes próprios em geral, mas, antes, do modo como a palavra foi introduzida na linguagem. Além disso, que um nome seja substituível por uma descrição, ou tran sformado em um predicado, não éuma questão decidida a priori, pois depende do contexto de uso e do modo de introdução. Em outras palavras, o sistema simbólico não é suficiente para fixar a contribuição semântica de um de seus sinais.

A diferença entre uma palavra que refere e uma que não refere, com efeito, devese ao modo como ela relaciona-se com as demais palavras da linguagem e, concomitantemente, ao modo como ela foi por essa linguagem introduzida em uma situação. A diferença entre as sentenças (1) "Pégaso não existe" e (2) "H ilda Furacão não troteia" éque, não obstante serem semelhantes sintaticamente, elas não 0 são semanticamente. (2) é verdadeira porque um objeto, 0 referente, tem um atributo codificado no predicado; (1) éverdadeira porque o nome não tem referente, a sua verdade deve-se a um aspecto muito diferente, lingüístico, do mundo. A diferença resulta, por um lado, do modo como o mundo está e, por outro, do modo como os nomes foram introduzidos na linguagem. A pesar de essa diferença estar em última instância ligada, por um lado, à intenção ou pragmática subjacente à linguagem em uso e, por outro, ao modo como 0 mundo é, ela é inteiramente semântica, pois ela tem sua razão suficiente no modo de significar das palavras.

3. Considere-se agora a questão de quais princípios estão envolvidos na descrição semântica de sentenças em que se afirma a inexistência de al go. N esse passo étentador ir em busca de respostas para questões do tipo "C omo épossível quealgo inexistente seja objeto de uma afirmação?" e "C omo uma sentença pode ser sobre algo que não existe?". I Ito levaria à suposição de que se uma asserção apenas pode ser sobre o que existe, então, segue-se que "algo inexistente" 
deve existir para ser objeto de asserções sobre o que não existe. $\mathrm{Ou}$ ainda, de que ser objeto de um discurso implicaria ser al go existente. Entretanto, penso que é possível resistir a semelhantes questões e inferências, com baseno argumento de que nem toda asserção sobre um objeto refere-se a uma entidade, tal como sustentei na seção anterior.

0 problema está na aceitação daquel as questões como ponto departida. Porém, elas introduzem um elemento ontológico quando o problema é semântico. Este problema aparece com mais clareza ali onde temos de reconhecer a legitimidade semântica de uma asserção e, simultaneamente, de admitir o colapso de nossas suposições acerca da relação entre a descrição das propriedades semânticas e a adequação da nossa noção de objeto correlata, como acontece nas asserções existenciais negativas. Considerese as asserções:

(1) Pégaso não existe.

(2) Hilda Furacão não troteia.

As sentenças utilizadas (1) e (2) são semanticamente legítimas e parecem semelhantes quanto à forma de construção gramatical. Porém, não obstante ambas poderem codificar asserções verdadei ras, em (2) realiza-se uma função semântica que não pode realizar-se em (1), a saber, a referência a um objeto particular.

A distinção necessária para elucidar essa diferença, em conformidade com a proposta de descrição semântica já desenvolvida, não écontudo entre dois modos de existência, mas, sim, entre 0 que é dito e o que existe. U ma sentença pode ser sobre algo e este al go não existir, justamentena medida em que o conteúdo semântico e, especificamente, o valor semântico de uma palavra, em posição de termo singular, possam ser dependentes de cadeias inferenciais, isto é, serem determinados não pelos nexos referenciais mas antes pelos nexos inferenciais. A diferença semântica de (1) e (2) dever-seia, por conseguinte, aos nexos inferenciais-referenciais que tornam as palavras "Pégaso" e "H ilda Furacão" significativas e, claramente, 
ao modo como o mundo é. A intenção de referir ou não dosfalantes nada pode fazer para mudar essa condição.

Tome-se a solução apresentada por R . C artwright ${ }^{15}$ para esse problema, a qual consiste em distinguir en tre referir e intentar referir, ${ }_{1}^{16}$ na linha daquela sugerida por Q uine. A sugestão de Cartwright, porém, é mais explícita quanto aos princípios semânticos em jogo, pois estabelece como objetivo a preservação de dois princípios ou intuições tidas como incontornáveis: primeiro, o princípio já enunciado de que "uma asserção somente pode ser sobrealgo existente"; 17 segundo, o princípio de que "predicar é dizer alguma coisa de ou sobre alguma coisa a que se refere", ${ }^{18}$ os quais, diga-se logo, apenas explanam ou reverberam a definição de termo proposicional antecipada no início.

Tendo em vista o que foi desenvolvido até aqui, nenhum desses dois princípios pode ser aceito sem qualificações e restrições. Por um lado, a assertibilidade não exige a referência (no sentido de designação de algo existente); por outro, o que é exigido na predicação é a determinação do conteúdo semântico e não a referência a alguma coisa (existente). N ote-se que não se trata apenas de uma disputa de palavras, pois a solução de C artwright está armada para sustentar que referir é designar algo existente. Entretanto, do ponto de vista da descrição semântica, essa solução não é satisfatória por um outro motivo já mencionado, a saber: ela transfere a explicação de uma diferença no conteúdo semântico sentencial para o âmbito da pragmática, ali onde não há nenhuma diferença lingüística que indique que isto esteja a ocorrer. Ao pressupor que predicar é dizer alguma coisa de ou sobre algo a que se refere, Cartwright não está senão a contornar as predicações existenciais negativas por meio da negação de que, em tais casos, ocorra a referência. Para isso ele introduz a noção ad hoc de intentar referir.

Pode-se, entretanto, reformular ${ }^{19}$ a solução de Cartwright usando a distinção entre aspectos inferenciais e aspectos referenciais do conteúdo semântico. A função semântica de "Pégaso" ede "Hilda Furacão", em (1) e (2) respectivamente, é idêntica. Não há, por 
conseguinte, nenhuma diferença quanto à forma gramatical dessas frases e, por isso mesmo, nenhuma diferença na superfície da sentença. A diferença detectável no conteúdo semântico das duas asserções decorre das conexões inferenciais que sustentam o uso daquelas duas palavras, cujo conhecimento énecessário para distinguilas semanticamente. Em outras palavras, é a aceitação da verdade de outras asserções ou, ao menos, a suposição de outras sentenças como exemplares ou regras, que faz a diferença, e não a intenção ou não de referir na situação de proferimento.

Desse modo recuperam-se as intuições que conduziram à solução sem extrapolar os limites da descrição semântica. A solução está em distinguir, não dois modos referir (real, fingido), mas antes doismodos pelos quais uma palavra pode exercer a função de termo singular. Para exemplificar, considere-se o contexto formado pelo proferimento destas três sentenças:

(1) Pégaso não existe, mas Hilda Furacão ainda vive.

(2) Hilda Furacão é tordilha.

(3) Pégaso é branco.

A diferença fundamental, do ponto de vista semântico, é que em (2) faz-se referência a um objeto, o que não acontece em (3). Em (3) utiliza-se um designador de um objeto introduzido no discurso a partir do campo discursivo, logo sem a suposição de uma dêixis primitiva, de tal modo que não há referência possível para esse designador. Mas do fato de que o designador não refere não se segue que não se possa determinar predicados cabíveis ao objeto e que seriam verdadeiros caso existisse o seu referente. Isto é o que acontece em (3), onde se diz que um predicado cabe ao objeto de discurso nomeado "Pégaso". Porém, do ponto de vista da descrição semântica, em termos de funções, papéis e estrutura semânticogramatical, (2) e (3) têm as mesmas propriedades. 0 queas diferencia é externo à semântica, não é dado pela linguagem: a existência e a não-existência de um dito objeto e os atos lingüísticos introdutores daquelas palavras. Pois que um objeto inexistente possa ser dito 
explica-se pelo modo como ele e as palavras foram introduzidos no discurso.

4. R etomemos o problema a partir de uma outra questão: se uma sentença é sobre um objeto, a existência ou não desse objeto interfere na determinação do conteúdo semântico da senten ça? Essa questão põese em vista da suposição plausível de que, se em uma sentença faz-se referência a um objeto, então tal objeto existe. Parece, pois, ser absurdo dizer que uma sentença refere-se a algo que não existe. Porém, seguese disso que ser sobre um objeto implica referir a uma entidade?

A gora, se entendermos que toda palavra significativa é também um objeto, seja uma sentença ou uma palavra subsentencial, e que a significatividade é uma propriedade desse objeto, decorrente de uma relação com algo diferente, então segue-se que, se uma sentença é significativa, tem de existir algo correlato a essa sentença. Pois, caso não exista tal correlato, ela não pode ser significativa. U ma tal posição seria considerada referencialista no que diz respeito à explanação da significatividade. Ela tem sido criticada com base no seguinte argumento. Ao dizer que uma sentença é significativa não se está a dizer que ela tem uma relação com alguma coisa existente. Essa objeção pode ser resumida com as palavras de M. H odges:

That a sentence is about something is simply one way to record certain facts about the language which has been used and, thus, does not involve making any claims about a supposed relation between sentence and object. ${ }^{20}$

O u seja, do fato que uma sentença seja sobre algo, não se segue que dela possa ser inferido que exista esse algo. Isto não é o mesmo que dizer que uma sentença não pode ser sobre um objeto específico. Interessa-me o modo como H odges justifica essa suposição, a saber, utilizando uma razão inferencialista. A solução deleé que uma sentença é sobre alguma coisa na medida em que ela 
retoma certos fatos sobre a linguagem utilizada. Em outras palavras, toda sentença é significativa porque retoma al go já dito, e isto constitui aquilo sobre o que ela é.

Essa solução possibilita aceitar que uma sentença seja significativa mesmo que nela a palavra sujeito não tenha referência e que não haja uma relação anafórica explícita com um termo explicitamente referencial. Assim, essa solução parece não ser capaz de distinguir entre as seguintes sentenças:

(1) Este que ali vem é do Campestre da Água N egra. Ele é o Negro Maciel.

(2) N egro Maciel é do Campestre da Água N egra. Ele vem e vai, vai e vem.

Na primeira, um indivíduo é introduzido sem necessitar que antes a linguagem já houvesse registrado a sua entrada como objeto de predicação ou como o correlato de um termo designador de alguma sentença verdadeira. $\mathrm{Na}$ segunda, ao contrário, isto está pressuposto. A distinção introduzida antes entre entidade e objeto aplica-se a este caso. Sobre o que a sentença (2) é depende do que foi dito anteriormente (quando da introdução do nome); a sentença (1), porém, é sobre algo e não depende do que foi dito antes. O ra, a solução inferencialista de H odges não pode aceitar esse uso.

Essa distinção é suficiente para mostrar que a solução de Hodges é incompleta. Por um lado, ao dizer que o fato de uma sentença ser sobre alguma coisa não implica que essa coisa exista, el ese esquece de mencionar aquelas sentenças cujo conteúdo semântico é dependente da existência do objeto nela designado. Por outro, ao dizer que na afirmação de que uma sentença é sobre alguma coisa se está apenas a recordar certos fatos lingüísticos, ${ }^{21}$ el e ignora que justamente alguns desses fatos implicam a referência imediata a uma entidade sem a intermediação dos recursos descritivos da linguagem, como no caso dos indicadores formais (dêiticos puros).

A motivação orientadora da solução de Hodges é também, como em Q uine e Cartwright, a tentativa de evitar as conclusões 
que Brentano e M einong retiraram da assim chamada intencionalidade da linguagem, pela qual todo termo designador teria um correlato intencional. $\mathrm{O}$ que $\mathrm{H}$ odges pretende é que a explanação da significatividade dê conta das relações inferenciais sem precisar postular entidades intensionais, tais como conceitos, sentidos, objetos abstratos etc., como contraparte on tológica das palavras significativas - pretensão com a qual eu concordo inteiramente, mas por razões diferentes.

A solução aqui defendida para esse problema preten de permanecer nos limites da semântica, sem adentrar no âmbito ontológico, mesmo que este seja restringido a uma ontologia do sujeito intencional. A minha solução consiste em distinguir dois modos pelos quais um termo designador pode contribuir para a determinação do conteúdo semântico de um contexto. Considere-se a sentença "João é o goleiro, mas hoje ele atua como centroavante", proferida assertoricamente. Se, na situação de proferimento, já se sabe quem é o indivíduo nomeado por "João", o pronome "ele" designa a pessoa chamada "João". Porém, se com essa frase é o nome "João" que está sendo introduzido através da caracterização de um indivíduo, aquele pronome, ao contrário, serve para fixar a referência do nome introduzido. 0 pronome ora funciona referencialmente, ora inferencialmente. Não énecessário postular duas formas de existência, nem apelar para entidades intencionais ou abstratas, para descrever a diferença de conteúdo semântico das sentenças, pois a distinção é entre modos de significação de palavras, os quais podem ser explanados inteiramente por meio da exposição dos nexos de remissão inferenciais e referenciais.

Essas considerações permitem a seguintehipótese: a existência de uma entidade, como correlato das palavras com função referencial, não é necessária para que a sentença seja significativa. Isso apenas seria necessário se todo termo fosse referencial. Mas, se é admitido que palavras possam ser termos genuínos sem referir, é possível que uma sentença contendo um termo singular não-referencial seja sobre um objeto e esse objeto não exista qua entidade. 
Desse modo, pode-se dizer que nem a referencialidade nem a inferencialidade exigem que o objeto de discurso seja uma entidade. A distinção necessária, do ponto de vista da descrição semântica, não é entre dois tipos de referência (real, fingida), nem entre dois tipos de entidades (existente, subsistente). N otese: objeto e entidade são dois conceitos semânticos que marcam a diferença do modo de introdução de al go no discurso. Isto podeser esclarecido retomandose a distinção del. Kant, entre conceito e existência, segundo a qual

através do conceito o objeto é pensado como adequado somente às condições universais de uma experiência empírica possível; através da existência, porém, é pensado como contido no contexto da experiência total. ${ }^{22}$

Disso se segue que o "conceito de objeto pode pois conter 0 que e o quanto quiser, mas para conferir-the a existência precisamos de qualquer maneira sair dele". ${ }^{23}$ Essa concepção foi retomada por G. Frege sob a forma da tese de que a existência é uma propriedade de conceitos e não de objetos. Desse modo, uma sentença como "H ilda Furacão existe" receberia a seguinte explicitação semântica: "Existe pelo menos uma coisa que é idêntica a Hilda Furacão". Todavia, para dizer isso é suficiente que tenhamos um conceito, ou significação determinada, associado à palavra "H ilda Furacão", e não que exista uma entidade designada por essa palavra. A existência, entretanto, seria necessária para a determinação do valor de verdade de certos ditos.

Porém, afastando-me de Frege, defendo que a função da pal avra "H ilda Furacão" nem sempre está determinada a priori (por estipulação prévia, por exemplo). Se ela foi introduzida através de uma indicação formal, podenão haver um conceito a ela associado. Transposta a tese de Kant para o vocabulário semântico, ela diria que, através de um termo designador significativo, um objeto é introduzido no discurso como adequado somente às condições gerais de uma possível asserção; através da predicação de existência, porém, ele é retomado como contido no contexto de uma asserção com 
termos referenciais redutíveis a um dêitico. Do que se segue, que seja lá qual for o conteúdo semântico codificado no termo designador, a afirmação da existência do objeto correlato lhe é exterior à semântica. Para efeitos de descrição semântica, um caso é marcado como objeto e outro como entidade. Essa terminologia, porém, pode ser enganadora, pois sugere uma distinção ontológica, embora na descrição semântica baste que a palavra seja marcada como referencial ou como inferencial.

Desse modo, o princípio de que uma proposição é sobre um objeto se na senten ça que a codifica ocorrer, como termo designador, uma palavra e esta designar o objeto, não implica a existência do objeto, mas tão-somente a sua dizibilidade. A dizibilidade, por sua vez, exige apenas que a palavra utilizada esteja ligada inferencialmente a outras palavras significativas. Em outras palavras, a dizibilidade exige apenas a identificabilidade, isto é, que aquilo que foi introduzido como objeto de discurso seja identificável, o que o mais das vezes é contingente e contextual, apenas determinável na situação de proferimento, e não implica a existência de uma entidade correlata. Portanto, do fato de que uma sentença seja sobre um objeto não se segue que haja uma entidade sobre a qual éa sentença. A propriedade de ser dizível ou expressável em uma linguagem é perfeitamente compatível com a inexistência. E, também, o existir não implica ser expressável em uma linguagem. A penas a confusão entre condições de existência, condições de expressabilidade e condições de significatividade poderia sugerir o contrário.

A identificação de uma palavra como termo proposicional, por conseguinte, por si só não exige postulação de existência de uma entidade a ela correlata, mas tão-somente a determinidade do conteúdo expresso, o que é garantido não pela intenção de referir, mas sim pelas regras sintático-semânticas que determinam as funções e os papéis codificados em uma palavra em um contexto discursivo numa situação de proferimento. Ser um termo, portanto, nem é uma propriedade de certas palavras, nem é uma decorrência das intenções do falante; antes, é uma relação de palavras, contextos e 
situações de proferimento. A lém disso, essa noção éprioritariamente semântica, sendo desnecessário o uso de noções quer ontológicas quer pragmáticas ou psicológicas para sua definição. ${ }^{24}$

ABSTRACT : In this paper I defend that semantic description and ontological postulation of entities are distinct issues, on the argument that semantic concepts are distinct of ontological ones. I will argue that the postulation of an entity imply an identification criteria, namely, the truth of an assertion of identity between two devices of designation. This seems to imply that the existence of the entity be warranted directly by the existence of an identification criteria. But this is a significance condition for a referential term, namely, that it codify an identifying description. This identifying description can't be confused with an existence condition for that entity.

Key words: Significance, entity, semantics, existence.

\section{Notes}

1. Frege, G. Kleine Schriften, "Was ist eine funktion", p. 278; "Funktion und Begriff", p. 126; G rundgesetze..., §1, p. 5. CARnAP, R. The logical syntax of language, $\S \S 41,42$. Q u INE, W. 0 ntological relativity, p. 15. Distinção esta incorporada por A. Tarski na própria definição da semântica ao tratar das relações entre expressões e objetos, "Theestablishment of scientific semantics", p. 401.

2. Esta restrição da abordagem ao ponto de vista da descrição semântica visa à elucidação das noções ali envolvidas; de modo algum ela indica a adesão ao procedimento de "ascensão semântica", o qual transformaria os problemas ontológicos em controvérsias acerca de palavras.

3. Lewis, C. I. "The modes of meanings", p. 237. QuINE, W. V. $M$ ethods of logic, p. 80. D efinições contemporâneas: "Terms are 'meaningfull' combinations of function symbols, variables and constants (together with commas and parentheses)" (EBbing haus, p. 15); "Terms are the nouns and pronouns of our language; they are the expressions which can be interpreted as naming an object. [...] The terms are defined to be those expressions which 
can be built up from the constant symbols and the variables by prefixing the function symbols. [...] If there are no function symbols, then the terms are just the constant symbols and the variables. [...]The terms are the expressions which are translated as names of objects (noun phrases), in contrast to the well formed formulas which are translated as assertions about objects." (EndERTON, 1972, p. 72-73).

4. Em termos simplificados, o inferencialismo semântico concebe a significatividade como fundada em relações de remissão internas (anafóricas) de um sistema simbólico e a referência a objetos como derivada; o referencialismo, ao contrário, toma como base da significatividade a relação entre palavras e objetos (dêixis) e explica as relações de remissão interna como superveniente e derivada.

5. Cf. Braida, C. R., Funções semânticas e complexidade da proposição. Linguagem e Filosofia. Florianópolis: NEL/ U FSC, 2002. (A nais do II Simpósio Internacional Principia, 2001).

6. Esta interpretação é referendada por D ummett e Evans: "Isto é suficiente para mostrar que pronomes demonstrativos não têm de ser entendidos como tacitamente associados com qualquer critério particular de identidade em cada ocasião de seus usos, e que, por essa mesma razão, eles não têm de ser em geral determinados como apanhando objetos" (Dummett. Seas of language, p. 326). "A demonstrative Idea of an object is not reducible to any other sort of Idea, and in particular cannot be regarded as a species of descriptiveidentification" (Evans. Varieties of reference, p. 173).

7. Nas palavras de R. B. M arcus (1993, p. 200): "No identity without entity".

8. Conforme a tradução de Luis H enrique dos Santos para From a logical point of view.

9. Idem, p. 222. 
10. Idem, p. 220.

11. Idem, ibidem.

12. Idem, p. 222.

13. Idem, ibidem.

14. $\operatorname{Almog}(1998$, p. 61).

15. Cartwright, R. Philosophical essays. Cf. en saio "Negative existentials".

16. Idem, p. 25 e 28.

17. Idem, p. 25 e 27.

18. Idem, p. 29.

19. Essa reformulação está sugerida nos próprios exemplos que C artwright emprega para sustentar os seus argumentos, de modo que ela não é propriamente uma solução diferente.

20. HOdGES, M. "On 'being about'", p. 5.

21. Idem, p. 8.

22. Kant, I. C rítica da razão pura, p. 301 (B628).

23. Idem, ibidem.

24. Este texto é uma versão modificada de parte do capítulo VIII de minha tese de doutorado, A complexidade do nexo semântico, defendida no Departamento de Filosofia da PU C -RJ, em agosto de 2001.

\section{Referêndias}

A LM OG, J. The subject verb object class I-II. Philosophical Perspectives, v. 12, p. 39-104, 1998.

BraidA, C. R. Funções semânticas e complexidade da proposição. Linguagem e Filosofia. Florianópolis: NEL/ U FSC, 2002.

Carnap, R. The logical syntax of language. Translated by A. Smeaton. Littlefield: Paterson, 1959. 
Cartwright, R. Philosophical essays. Cambridge: MIT Press, 1987.

Dummett, M. The seas of language. O xford: Clarendon Press, 1993.

Ebinghaus, H. D.; Flum, J.; Thomas, W. M athematical logic. 2. ed. N ew York: Springer-Verlag, 1996.

Enderton, H. B. A mathematical introduction to logic. San Diego: A cademic Press, 1972.

Evans, G. The varieties of reference. Edited by J. M cD owell. 0 xford: Clarendon Press, 1982.

Frege, G. K leine Schriften; hersg. I. Angelelli. 2. Aufl. Hildesheim: G. OIms, 1990.

1962.

. G rundgesetze der A rithmetik. 2. Aufl. Hildesheim: G. O Ims,

Hodges, M. On being about. M ind, v. LXXX, n. 317, p. 1-16, 1971.

KAnt, I. Crítica da razão pura. Tradução de V. Rohden e U. B. M oosburger. São Paulo: V. Civita, 1983.

Marcus, R. B. Modalities: philosophical essays. Oxford: Oxford University Press, 1993.

Quine, W. V. Word and object. C ambridge: MIT Press, 1960.

. 0 ntological relativity \& other essays. N ew York: Columbia University Press, 1969.

. M ethods of logic. Revised edition. London: Routledge \& Kegan Paul, 1972.

. From a logical point of view. 2. ed. Cambridge: $\mathrm{H}$ arvard University Press, 1980.

TARSKI, A. L ogic, semantics, metamathematics. Edited by J. Corcoran. Translated by J. H. W oodger. 2. ed. Indianapolis: H ackett, 1983. 